UC-15

lssued: January 1986

LA--10640-MS

DE86 007588

\title{
Three-Energy Gamma-Ray Absorptiometer (TEGA) for Nondestructive Assay of Plutonium and Uranium in Solution
}

\author{
Massimo Aparo*
}

\author{
DISCLAIMER
}

was account of work sponsored by an agency of the United states the United States Government nor any agency ther liability or responsiGovernment. Neither the Uniry, express or implied, or assumes any legal habily or product, or employees, makes any warnty, exes, or usefulness of any information, apparatus, prights. Referbility for the accuracy, compents that its use would no! infringe privately own trade name, trademark, process disclosed, or represents that its use wouct, process, or service by trade name, tradent, recomence herein to any specific coms not necessarily constitute or imply its endoreof. The views manufacturer, or otherwise does not ned States Government or any agency therect those of the

and opinions of authors expressed herein do nof

"Visiting Scientist at Los Alamos. E.N.E.A.-C.R.E. Casaccia, Div. COMB-MEPIS, 0060 Rome, ITALY. 


\section{CONTENTS}

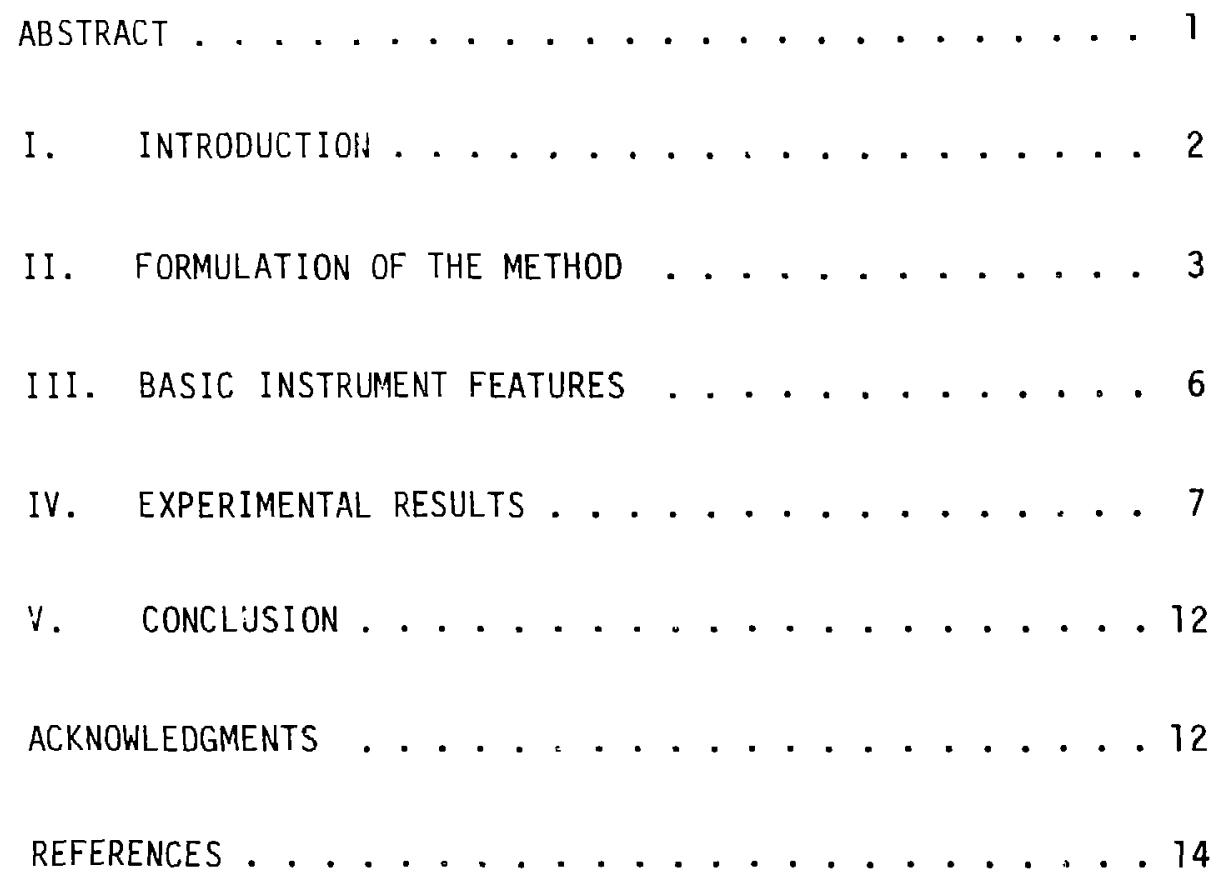


FOR NONDESTRUCTIVE ASSAY OF PLUTONIUM AND URANIUM IN SOLUTION

by

Massimo Aparo

\begin{abstract}
An experimental approach for the rondestructive characterization of plutonium and uranium solutions is presented. The technique relies on the transmission of photons of three different properly chosen energies and allows an independent and simultaneous determination of plutonium and uranium by the different absorption of the two elements in the range of $\mathrm{K}$-edge energies. The performances achievable have been evaluated through measurement of a set of solutions using the hardware of the compact $\mathrm{K}$-edge densitometer. The plutonium and uranium concentrations ranged from 50 to $150 \mathrm{~g} / \mathrm{l}$. In this concentration range, the relative precision is below $3.0 \%$ for uranium assay and below $6 \%$ for plutonium assay. Further improvements of the performances of the technique are discussed.
\end{abstract}




\section{INTRODUCTION}

A nondestructive technique for independent and simultaneous determination of plutonium and uranium in solution is currently under development. The measuring technique relies on the transmission of photons at three different properly chosen energies and is based on differential absorption of plutonium and uranium in the range of K-edqe energies. This technique can be considered as a further development of dual energy x-ray absorptiometry (DEXA), 1 which is based on differential absorption in the range of L-edge energies. DEXA is a nondestructive technique for the assay of mixed special nuclear material (for instance, thorium and uranium or uranium and plutonium) in solution. This measuring technique relies on the transmission of photons of two different energies and allows independent evaluation of one element (thorium or uranium), with the second one (uranium or plutonium) being determined on the basis of the total heavy elements. Field testing of the DEXA instrument for assay of thorium-uranium mixed solutions demonstrated assay precisions of better than $1 \%$ in a counting time of $4000 \mathrm{~s}$ for both elements in the range from 30 to $70 \mathrm{~g} / \mathrm{l}$. Alsu demonstrated was the potential of using the instrument for process control or as a safeguards assay tool in reprocessing facilities.

The DEXÁ technique appears to be unsatisfactory for assay of uraniumplutonium mixed solutions having high plutonium concentration because spontaneous emissions from ${ }^{238} \mathrm{Pu}$ overlap the transmitted peaks.

To overcome this problem and to make the method insensitive to the presence of fission products, we decided to shift the analysis to the range of K-edge energies where it becomes possible to independently assay both uranium and plutonium. For this reason, a feasibility study of the TEGA technique was carried out and the results were presented at the Sixth ESARDA conference. 2

This report describes the physical principles of the technique and presents the first experimental results obtained using the same measuring head as that used with the compact K-edge densitometer (KED), ${ }^{3}$ an instrument developed at Los Alamos National Laboratory.

\section{FORMULATION OF THE METHOD}

Use of the TEGA technique in assaying solutions for plutonium and uranium concentration involves the measurement of the transmission through the solution 
of three photons at energies $E_{0}, E_{m}$, and $E_{h}$. The upper part of $F i g .1$ shows the behavior of the photon absorption coefficient $\mu$ around the $K$-edge region of heavy eiements (plutonium, uranium). (The elements are dissolved in a low-Z acid medium.) The lower and middle parts of Fig. 1 show the transmitted photon intensities for the three photopeaks at the energies $E_{\ell}, E_{m}$, and $E_{h}$.

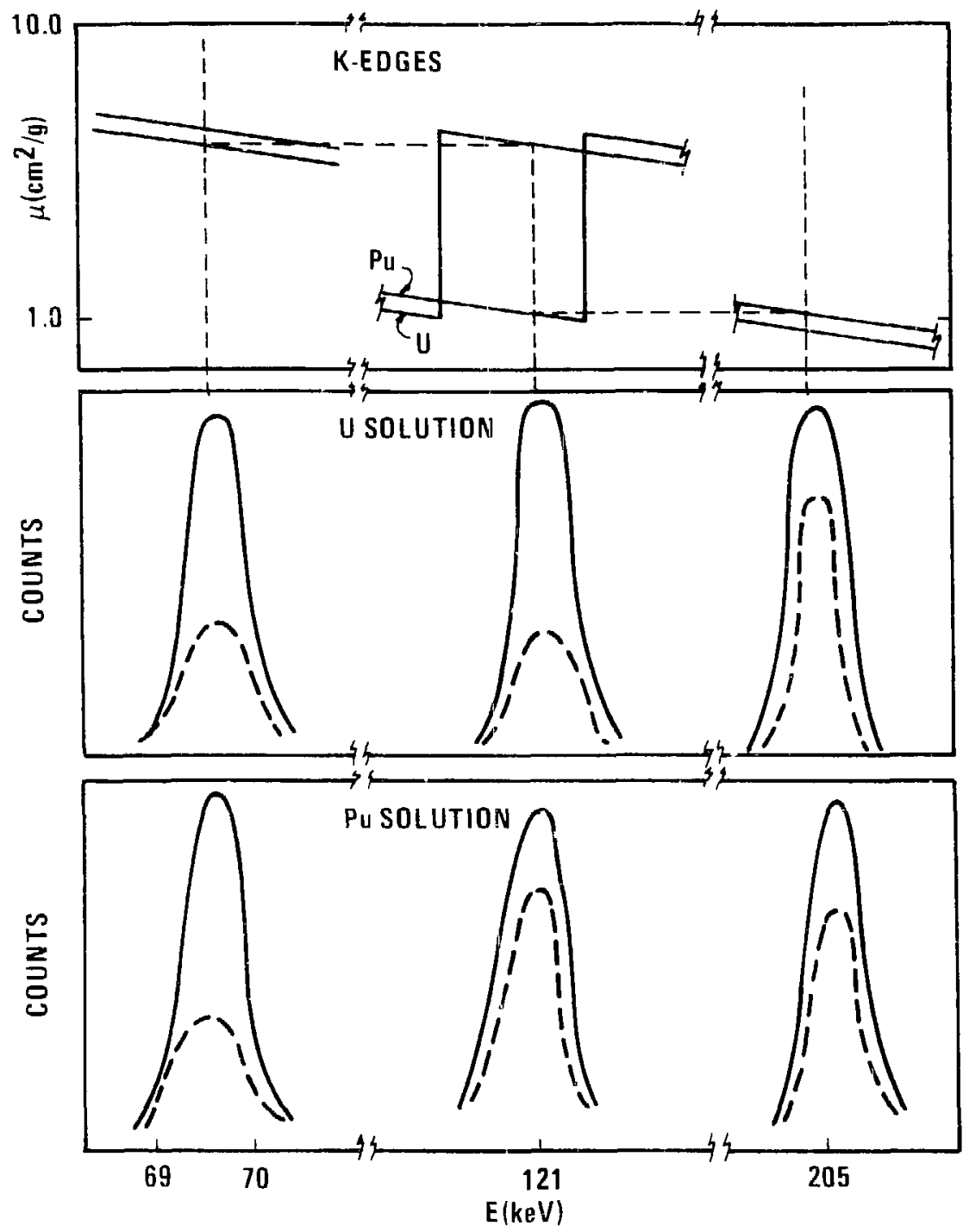

Fig. 1. Upper: an expanded view of the mass attenuation coefficient around the K-edge region vs gamma-ray energy for plutonium and uranium. Middle: a schematic representation of the transmitted photon intensities for "blank" (solid curves) and uranium-bearing solution (dotted curves). Lower: a schematic representation of the transmitted photon intensities for "blank" (sclid curves) and plutonium-bearing (dotted curves) solution. 
The transmissions of the photons at these three energies through a thickness $d$ of sample solution are

$$
\begin{aligned}
& -\ell n T_{\ell}=\left[\mu_{P_{u}}\left(E_{\ell}\right) \rho_{P_{u}}+\mu_{u}\left(E_{\ell}\right) \rho_{u}\right] d \\
& -\ell n T_{m}=\left[\mu_{p u}\left(E_{m}\right) \rho_{p_{u}}+\mu_{u}\left(E_{m}\right) \rho_{u}\right] d \\
& -\ell n T_{h}=\left[\mu_{P u}\left(E_{h}\right) \rho_{p u}+\mu_{u}\left(E_{h}\right) \rho_{u}\right] d .
\end{aligned}
$$

The transmissions $T_{\ell, m, h}$ are the ratios of photopeak intensities $R_{l, m, h} / R_{\ell, m, h}^{\star}$, where the intensities $\because a$ the denominator are the "blank" soluticn values and those in the numerator are solution values.

If $E_{\ell}, E_{m}$, and $E_{h}$ are chosen to satisfy the following conditions,

(1) $E(U$ K-edge $)<E_{m}<E(P u K$-edge $)$

(2) Back balancing: $\mu\left(U, E_{\ell}\right)=\mu\left(U, E_{m}\right)$

(3) Forward balancing: $\mu\left(P u, E_{m}\right)=\mu\left(P u, E_{h}\right)$,

then

$$
\begin{gathered}
\rho_{P_{U}}=\frac{-\ell n\left(T_{\ell} / T_{m}\right)}{\left[\mu\left(P u, E_{\ell}\right)-\mu\left(P u, E_{m}\right)\right] d} \\
\rho_{U}=\frac{-\ell n\left(T_{m} / T_{h}\right)}{\left[\mu\left(U, E_{m}\right)-\mu\left(U, E_{h}\right)\right] d} .
\end{gathered}
$$


Although it is possible to find radioisotopes that emit a line between the $K$ edges of uranium and plutonium, satisfying both balancing conditions appears not to be achievable. Nevertheless we can create these conditions by correcting the measured transmissions $T_{\ell}^{\star}$ and $T_{h}^{\star}$ to the values they would assume at energy $E_{\ell}$ and $E_{h}$. This correction is straightforward because of the linear behavior of $\ell n \mu(E)$ vs $\ell n(E)$, at least in a limited energy range far away from edges :

$$
\begin{aligned}
& \ln T_{h}=\left[\mu\left(P u, E_{m}\right) /\left(\mu\left(P u, E_{n}^{\star}\right)\right] \ln T_{h}^{\star}=B \ln T_{h}^{\star}\right. \\
& \ln T_{\ell}=\left[\mu\left(U, E_{m}\right) / \mu\left(U, E_{\ell}^{\star}\right)\right] \ell n T_{\ell}^{\star}=\alpha \ln T_{\ell}^{\star} .
\end{aligned}
$$

Expressing $P_{u}$ and $U$ as a function of the measured transmissions $T_{\ell}^{\star}, T_{m}, T_{h}^{\star}$, at at energies $E_{\ell}^{\star}, E_{m}$, and $E_{h}^{\star}$, respectively,

$$
\begin{aligned}
& \rho_{P u}=\frac{-\alpha \ell \ell T_{\ell}^{\star}+\ell n T_{m}}{\left[\alpha \mu\left(P u, E_{\ell}^{\star}\right)-\mu\left(P u, E_{m}\right)\right] d} \\
& \rho_{U}=\frac{-\ell, n T_{m}+B \ell n T_{h}^{\star}}{\left[\mu\left(U, E_{m}\right)-\alpha \mu\left(U, E_{h}^{\star}\right)\right] d} .
\end{aligned}
$$

To fulfill these requirements, a ${ }^{75}$ Se source has been chosen despite its short half-life of 120 days, and the measurements have been carried out using the lines at $96.733 \mathrm{keV}\left(E_{\ell}\right), 121.115 \mathrm{keV}\left(E_{m}\right)$, and $198.596 \mathrm{keV}\left(E_{h}\right)$. 


\section{BASIC INSTRUMENT FEATURES}

The compact $K$-edge densitometer has been used to allow testing and evaluation of the method. This instrument consists of (1) a measurement head (Fig. 2) that allows measurement through a glove port of a glove box; (2) a portable planar detector $\left(10 \mathrm{~mm}\right.$ by $200 \mathrm{~mm}^{2}$ with a resolution of $510 \mathrm{eV}$ at $\left.122 \mathrm{keV}\right)$; and (3) a portable, computer-based multichannel analyzer (4096-channel Davidson). For our measurements, a cadmium shield $(2 \mathrm{~mm}$ thick) was placed in front of the detector to achieve a lower energy cutoff that kept the deadtime of the multichannel analyzer below 20\%. a solutions were contained in plastic vials with a transmission path of $2 \mathrm{~cm}$. The distance between the source and the detector was about $28 \mathrm{~cm}$, and the diameter of the output collimator was $0.5 \mathrm{~cm}$. The ${ }^{75}$ Se transmission source, located in a holder at one end of the measuring head, had a nominal activity of $52 \mathrm{mCi}$, but at the date of measurements it was 4 months old. An amplifier shaping time of $3 \mu \mathrm{s}$ was used during data acquisition, and pulse pileup rejection was employed. A "straight-through" measurement with a "blank" solution $\left(3 \mathrm{M} \mathrm{HNO}_{3}\right)$ was collected every day to obtain the

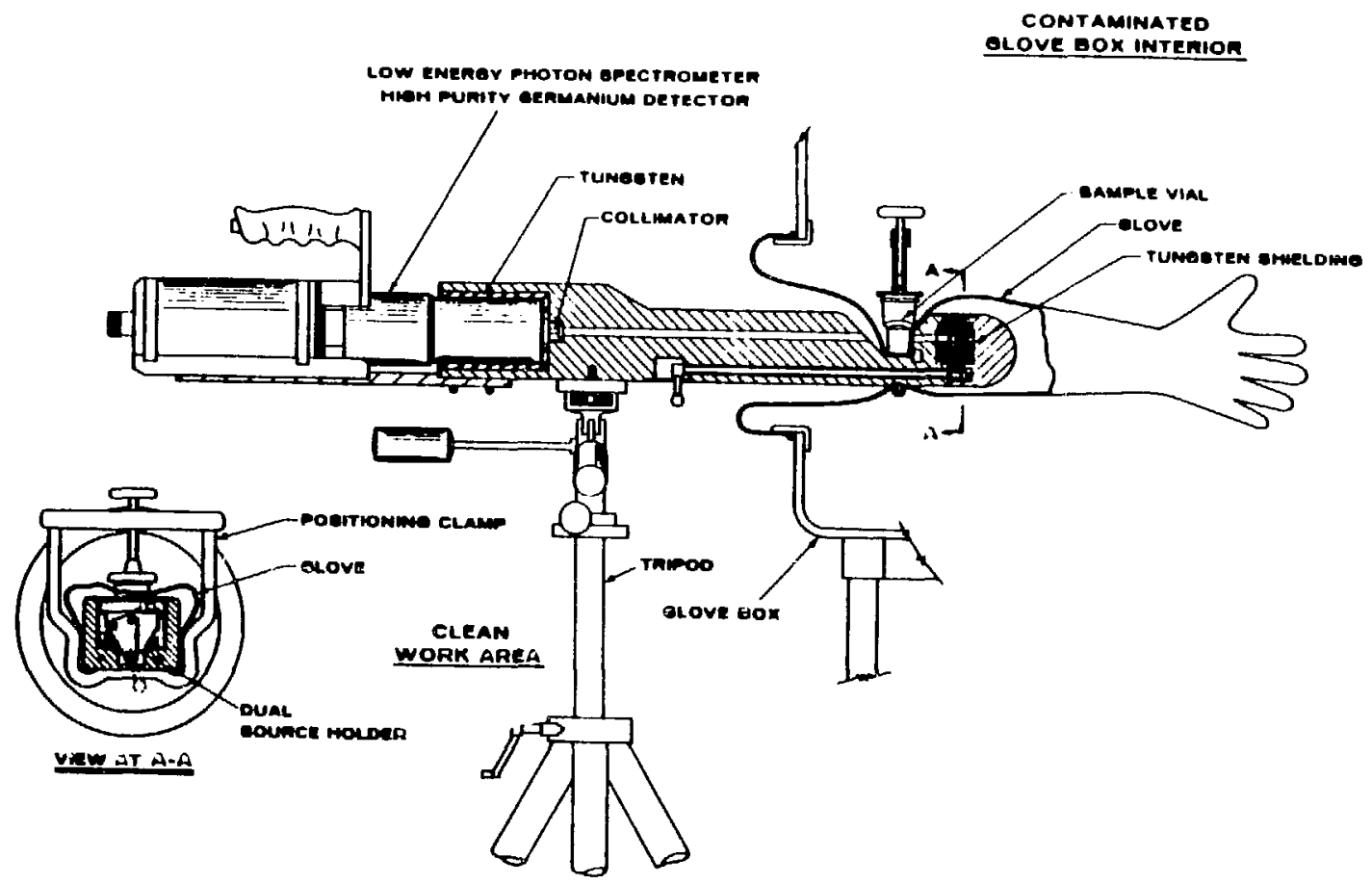

Fig. 2. Measuring head of the compact K-edge densitometer used for testing the performance of the TEGA technique. 
unattenuated values $R_{l, m, h}^{*}$. Because the method is based on ratios of transmitted peaks of a single radioisotope, it was not necessary to introduce a time correction that takes into account the half-life of ${ }^{75}$ Se. A typical spectrum of the transmitted radiation is shown in Fig. 3.

IV. EXPERIMENTAL RESULTS

A set of standard (pure plutonium or uranium as well as mixed) aqueous solutions $\left(3 \mathrm{M} \mathrm{HNO}_{3}\right.$ ) has been prepared to calibrate and test the performance of the technique. Calibration of the instrument has been carried out by using one pure plutonium and one pure uranium standard solution with a counting time of $4000 \mathrm{~s}$. However, the choice of the calibration solutions does not affect the results.
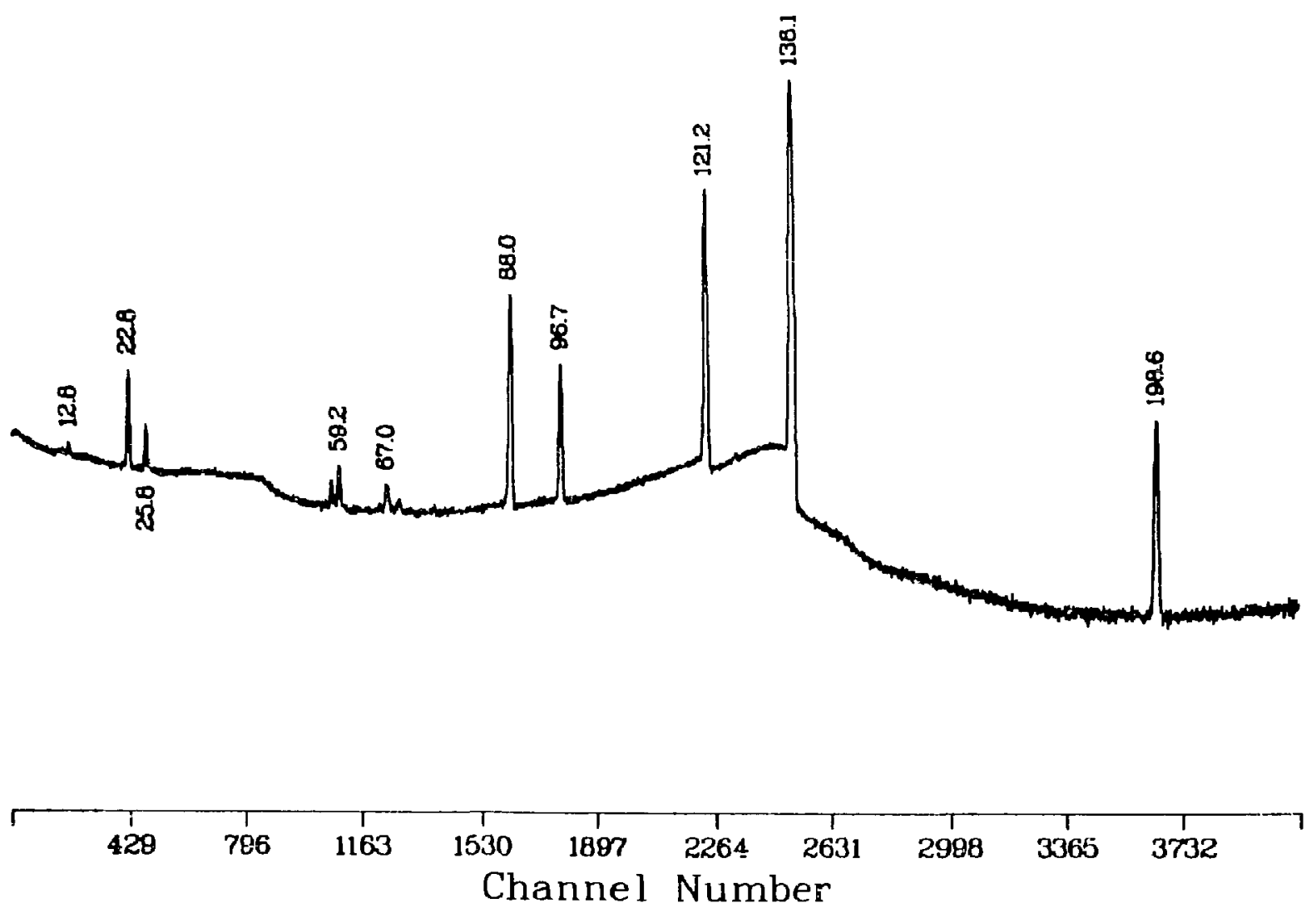

Fig. 3. Typical straight-through snectrum of transmission source. The 88-keV peak from a $109 \mathrm{Cd}$ source can be used for counting loss correction. 
Figure 4 is a plot of the calibration constant $(\Delta \mu d)$ vs plutonilum concentration. For each plutonium sample, the correction constant was determined both by measurements (as the ratio between the $97-$ and 127-keV transmitted peaks for different uranium solutions) and by calculation (from literature values). Figure 5 is the same plot of calibration constants, but vs uranium consentration.

The same standard solutions have also been measured with the KED system to compare the performances of the two techniques, TEGA and KED. The results obtained are summarized in Table I and compared with the known values; related uncertainties (io) are al so given.

It is worthwhile to point out that the difference in respective uncertainties between uranium and plutonium is principally due to the large correction factor 12.1 i applied to the transmission at energy $E_{l}$ for satisfying the back balancing condition. Such a problem was not noticed in the previous feasibility study because the evaluation of the expected performances was carried out using the line at $66.11 \mathrm{keV}$, closer to the ideal energy $E_{1}(70 \mathrm{kel})$. The estimated correction factor of the $66-\mathrm{keV} l$ ine is 0.8 . Currently, the experimental apparatus will not allow the measurement of the $66.11-\mathrm{keV}$ line.

Figures 6 and 7 show the relative assay precision expected for plutonium as well as for uranium as a function of the U/Pu ratio in a counting time of $2000 \mathrm{~s}$. The blocks on the figures represent the measured relative precision.

It riust be pointed out that, in principle, the technique is sensitive to the matrix material, which is taken into account through the measurement of "blank" solution. So matrix variation (for instance, fluctuation of acid molarity) may introduce systematic errors that are independent of uranium and plutonium concentration. Calculations have shown that a $0.5 \mathrm{M}$ variation in the acid $\left(\mathrm{HNO}_{3}\right)$ molarity introduces biases of about $0.5 \mathrm{~g} / \mathrm{l}$ in the assay of plutonium and about $0.15 \mathrm{~g} / \mathrm{l}$ in the assay of uranium. In both cases, by correcting the transmission data for the presence of the other heavy element, we have actually enhanced the effect of the variation of the matrix. The large difference in the two correction factors causes the introduced bias in the plutonium determination to be much greater than the bias in the uranium measurement. 


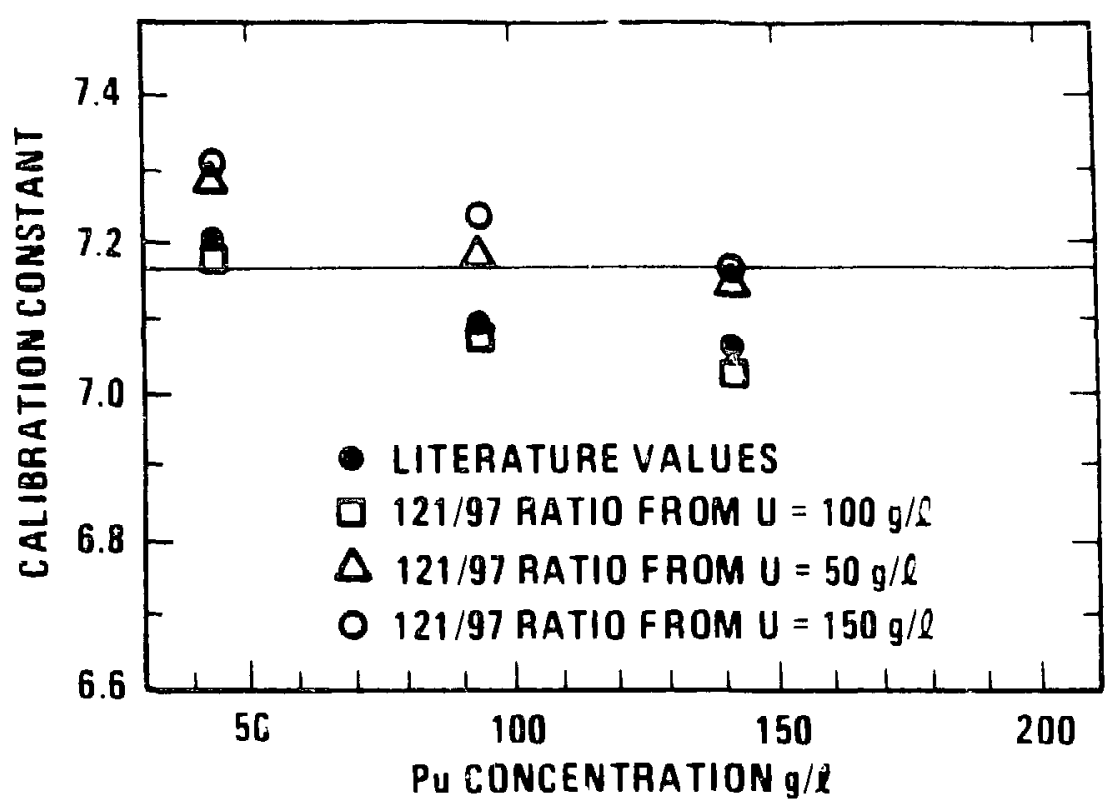

Fig. 4. A plot of the calibration constant 4 ild in $\mathrm{cm}^{3} / \mathrm{g}$ vs plutonium concentration. Each point represents a different correction factor $\alpha$ determined by the ratio between the 121- and 97-keV transmitted peaks for each uranium solution or by literature values.

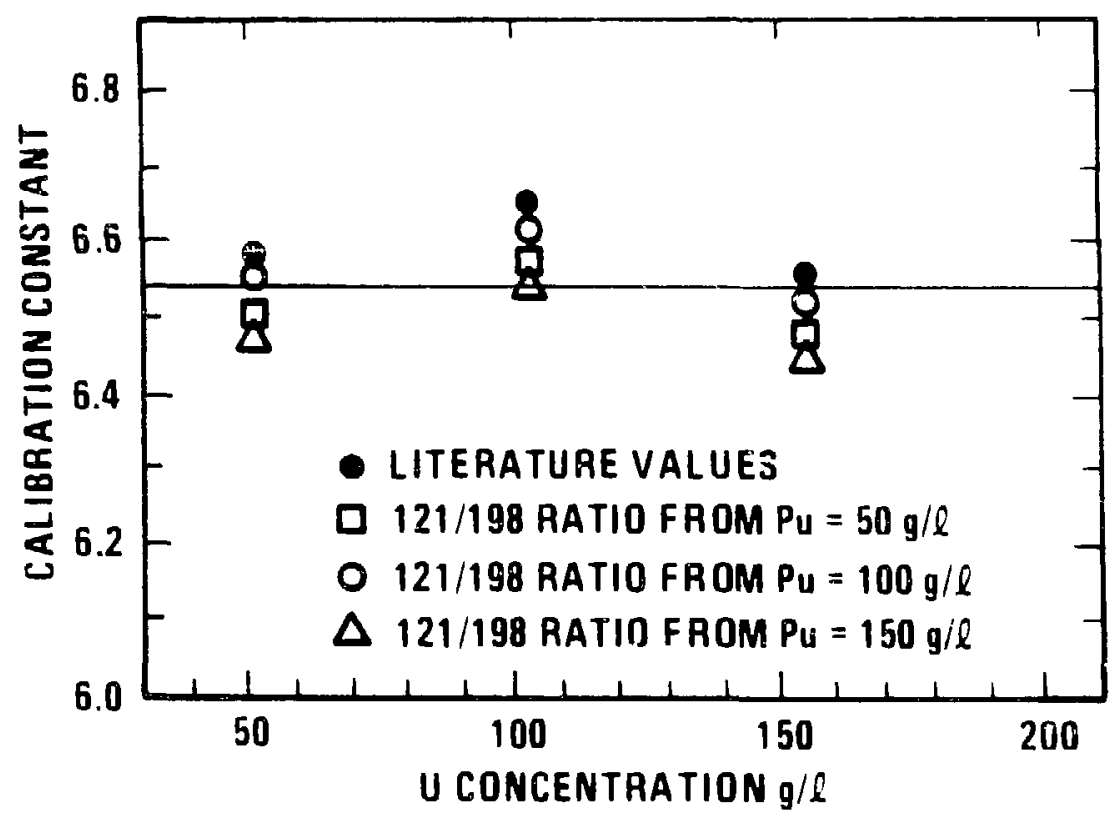

Fig. 5. The same plot as in Fig. 4, but vs uranium concentration. The correction factor $B$ was determined by the ratio between the 121- and 198-keV transmitted peaks for each plutonium solution or by literature values. 
TABLE I

COMPARISON T,F CONCFNTRATION MEASUREMENT RESULTS

\begin{tabular}{|c|c|c|c|c|c|c|c|}
\hline \multicolumn{2}{|c|}{ Known Concentration } & \multicolumn{4}{|c|}{$\operatorname{TEGA}^{\mathrm{a}}$} & \multicolumn{2}{|c|}{$\begin{array}{cl}\text { KED } & \\
\text { Measured Concentration }\end{array}$} \\
\hline $\begin{array}{l}\text { Plutonium } \\
(\mathrm{g} / \mathrm{\ell}) \\
\end{array}$ & $\begin{array}{l}\text { Uranium } \\
(\mathrm{g} / \mathrm{l}) \\
\end{array}$ & \multicolumn{2}{|c|}{$\begin{array}{l}\text { Plutonium } \\
(\mathrm{g} / \mathrm{l})\end{array}$} & \multicolumn{2}{|c|}{$\begin{array}{c}\text { Uranium } \\
(\mathrm{g} / \mathrm{\ell})\end{array}$} & \multicolumn{2}{|c|}{$\begin{array}{l}\text { Plutonium } \\
(\mathrm{g} / \mathrm{e})\end{array}$} \\
\hline 44.8 & - & 45.49 & \pm 3.27 & 0.219 & \pm 1.58 & 44.31 & \pm 1.64 \\
\hline 94.0 & - & \multicolumn{4}{|c|}{ calibration } & \multicolumn{2}{|c|}{ calibration } \\
\hline 142.5 & - & 141.78 & \pm 4.07 & -1.06 & \pm 1.76 & 142.6 & \pm 2.61 \\
\hline 223.2 & - & 234.02 & \pm 5.24 & -2.92 & \pm 1.96 & 228.8 & \pm 3.76 \\
\hline - & 51.9 & -0.717 & \pm 3.03 & 51.30 & \pm 1.46 & 0.865 & \pm 1.46 \\
\hline - & 103.7 & \multicolumn{4}{|c|}{ calibration } & -4.65 & \pm 1.5 \\
\hline- & 155.6 & -2.46 & \pm 3.69 & 153.19 & \pm 1.67 & -1.21 & \pm 1.53 \\
\hline 45.2 & 103.7 & 48.43 & \pm 4.05 & 98.4 & \pm 1.76 & 40.10 & \pm 1.63 \\
\hline 68.6 & 77.8 & 69.38 & \pm 4.08 & 77.26 & \pm 1.77 & 66.83 & \pm 1.82 \\
\hline 93.1 & 51.9 & 97.1 & \pm 3.73 & 51.14 & \pm 1.63 & 88.78 & \pm 1.98 \\
\hline i03.7 & 155.6 & 108.8 & \pm 4.97 & 152.98 & \pm 1.63 & 102.8 & \pm 2.23 \\
\hline
\end{tabular}

a The TEGA technique used a 2000-s counting time.

bThe KED technique used a 30 Su-s counting time. 


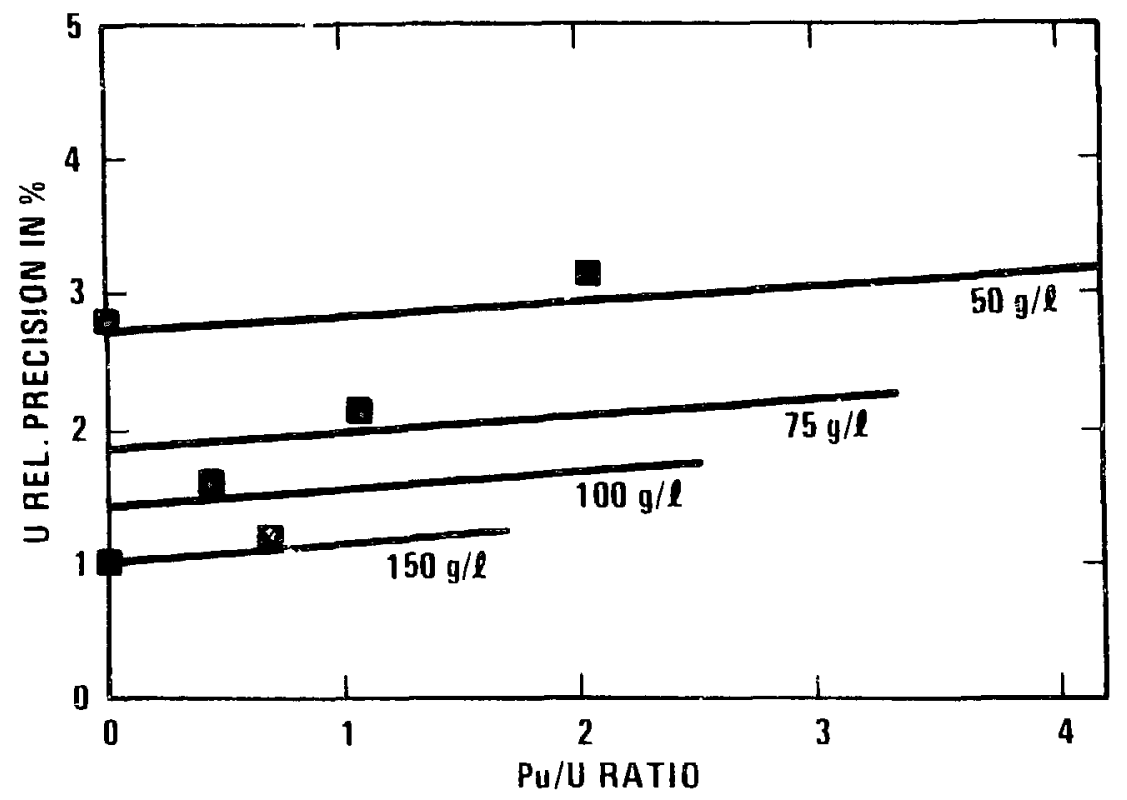

Fig. 6. A plot of expected per cent precision (10) vs Pu/U ratio fur a $20050-s$ counting time and different uranium concentrations. The blocks represent the measured precision.

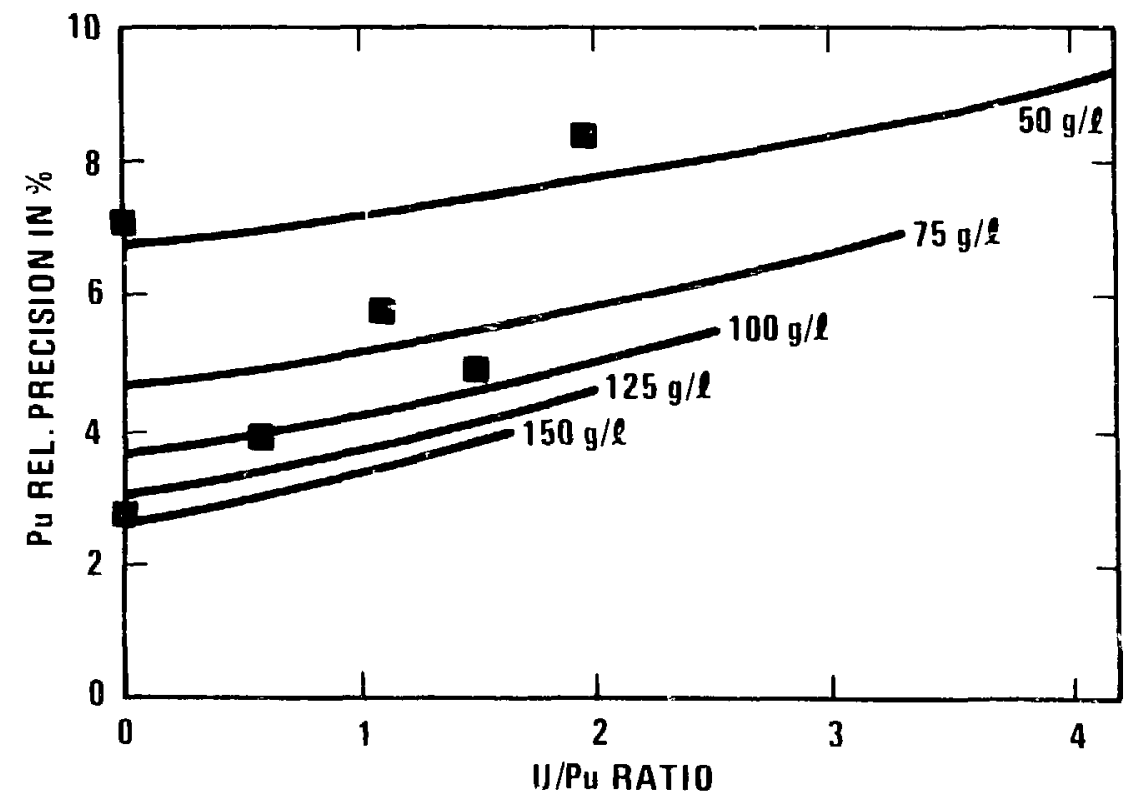

Fig. 7. A plot of expected per cent precision (10) vs the U/Pu ratio for a 2000-s counting time and different plutoniuin concentrations. The blocks represent the measured precision. 
V. CONCLUSION

The instrumental approach described here appears interesting because it allows simultaneous and independent determination of two heavy elements, plutonium and uranium, that often flow in the same stream in different parts of the nuclear fuei cycle (that is, in reprocessing plants, conversion plants, and others). In addition, by optimizing the design of the measuring head, the instrument might work both in an active mode (determination of plutonium and uranium concentration) and ir a passive mode (isotopic analysis of plutonium), allowing a complete characterization of the assay solution.

Further improvement of the assay precision appears feasible either by (1) rearranging the measuring head to reduce the distance between the source and the detector and introducing a stronger ${ }^{75}$ Se source (for instance, activity $100 \mathrm{mCi}$ ) in such a way as to use the 66.11-keV line, or (2) because the 66.11keV line is the mist inportant cause of imprecision, by replacing the 75 se source with a mixed source of ${ }^{75} \mathrm{Se}$ and ${ }^{133} \mathrm{Ba}$. According to calculations made on the basis of the experimental resuits, the first alternative [use of a strcnger ${ }^{75} \mathrm{Se}$ source (activity $100 \mathrm{mCi}$ ) with a shorter distance between the source and detector] should allow measurement of plutonium with a relative precision under $2.5 \%$ in a counting time of $1000 \mathrm{~s}$. The second alternative [use of a mixed source of ${ }^{75} \mathrm{Se}$ and ${ }^{133} \mathrm{Ba}$ (with activities of 25 and $10 \mathrm{mC}$, respectively) and the same measuring device we used in our study] should allow a relative precision under $2 \%$ in a counting time of $1000 \mathrm{~s}$. In this case, the $81-\mathrm{keV}$ line of ${ }^{133}$ Ba would replace the $66-\mathrm{keV} 1$ ine of ${ }^{75} \mathrm{Se}$.

The relative precisions achievable by these two different arrangements for plutonium assay are plotted vs the U/Pu ratio in Figs. 8 and 9 .

\section{ACKNOWLEDGMENTS}

I would like to acknowledne the support given by members of the Safeguards Assay Group without which I would not be able to carry out this work. I would especially iike to thank $R$. Augustson for his continuous helpful suggestioris as well as for his comments on this report and $L$. R. Cowder for handling the plutonium and uranium solutions and for preparing the measuring head. 


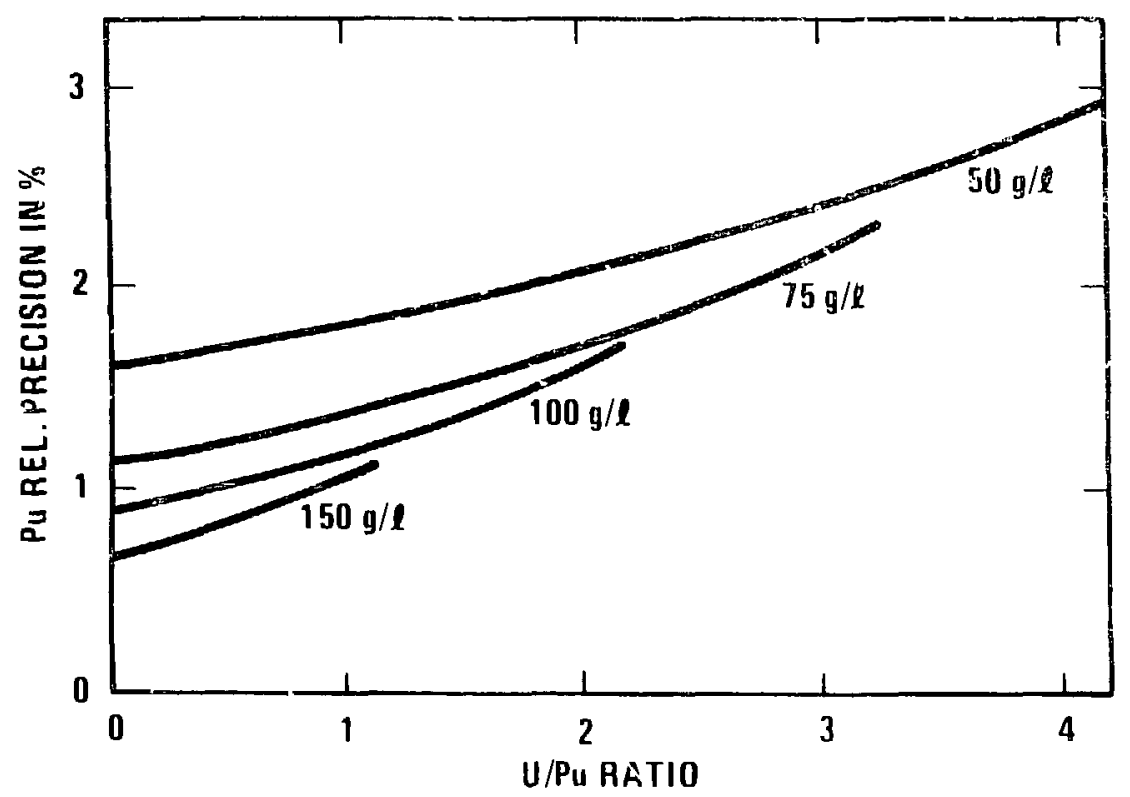

Fig. 8. A plot of the expected relative precision in plutonium assay $v S \mathrm{U} / \mathrm{Pu}$ ratio for $1000-\mathrm{s}$ counting time and different plutonium concentrations. The $75 \mathrm{Se}$ source activity was assumed to be $100 \mathrm{mCi}$; that of the distance source detector, $14 \mathrm{~cm}$.

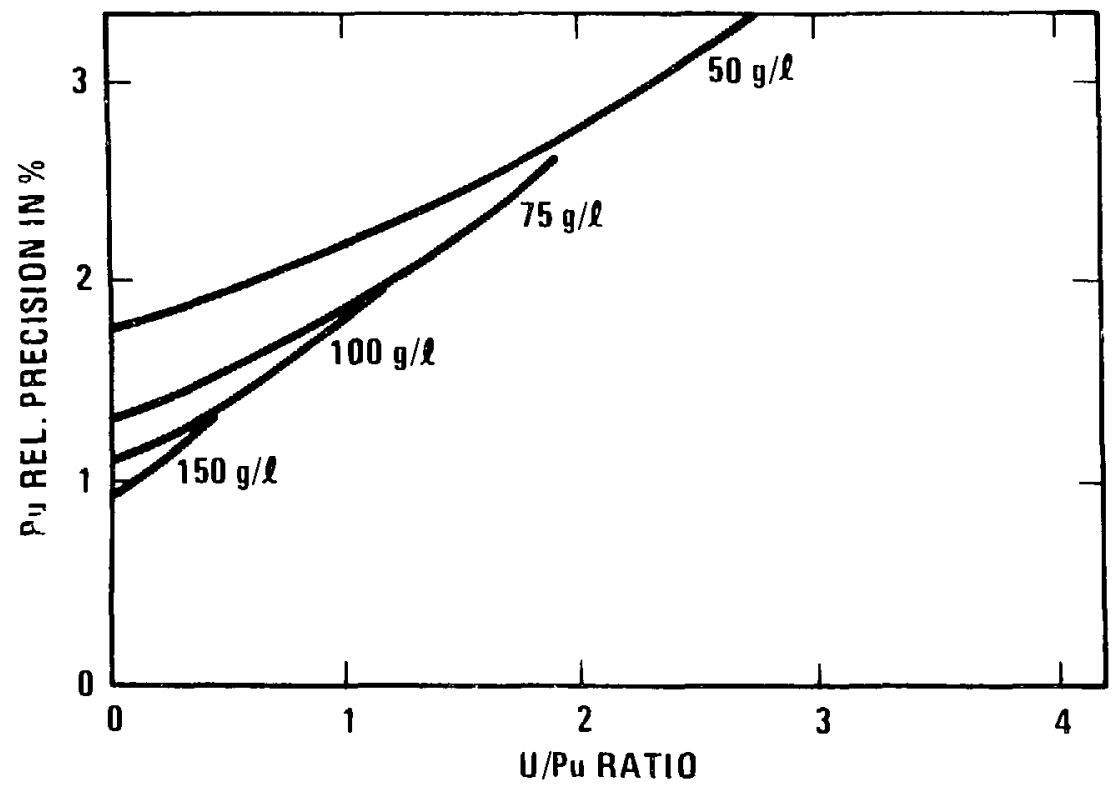

Fig. 9. The same plot as Fig. 9, but the source was assumed to be a mixed $75 \mathrm{Se}$ and $133 \mathrm{Be}$ source, with activities of 25 and $10 \mathrm{mci}$, respectively. 


\section{REFERENCES}

1. M. Aparo, B. Mattia, F. V. Frazzoli, and P. Zeppa, "Dual Energy X-Rays Absorptiometer for Non Destructive Assay of Mixed Special Nuclear Material in Solution," in Proceedings of the Fifth Annual Symposium on Safeguards and Nuclear Materiai Management, Versailles, France (1983), pp. 271-275.

2. M. Aparo, P. Cresti, F. V. Frazzoli, R. Remetti, C. Vicini, and P. Zeppa, "Characterization of Plutonium Solutions (Densitometry and Isotopic Analysis by Gamma Spectrometry)," in Proceedings of the Sixth Annual Symposium on Safeguards and Nuclear Material Management, Venice, Italy (1984), pp. 249-253.

3. L. R. Cowder, S. F. Klosterbuer, R. H. Augustson, A. Esmailpour, R. Hawkins, and E. Kuhn," A Compact K-Edge Densitometer," in Proceedings of the Sixth Annual symposium or Safeguards and Nuclear Material Management, Venice, ItaTy (1994), pp. 26T-268. 